\title{
Relationship of personal and valuable characteristics with cultural reflection of Egyptian Drama: Case study of Talla village, Minia governorate, Egypt
}

\author{
El-Reedy G. H. M., Hassan Hala O. Y." \\ Agricultural Economic Department, Faculty of Agriculture, Minia university, Minia, Egypt
}

\begin{abstract}
The study aimed to determine the degree of cultural reflection to social drama in Talla village, Minia governorate, Egypt, as well as, the nature of the relationship between value variables and the degree of cultural reflection. The main findings indicated the morale of the relationship between the cultural value of drama and the degree of ingenuity of social values, marital status and type of family. The study recommended the importance of drama awareness.
\end{abstract}

Keywords: personal characteristics, cultural reflection, Egyptian Drama, Minia governorate. 


\section{Introduction}

Art is one of the means of communication between people, and as a person transmits his thoughts to others through speech, he transmits his emotions through art, which is an innate ability that people possess to transmit their emotions to others through movements, melodies, lines, colors, sounds, and various verbal and expressive images, and given the connection From an important role in human society, without it, groups cannot arise, as it is the bearer of the social process, and it is the means that a person uses to organize and stabilize his social life, and through it he transmits forms and types of his social life from one generation to another, through expression, registration and education logical (Al-Masry, 2010). Believes that drama is every artwork based on a selfstanding unit and has rules and laws of its own that differ from the laws of ordinary human life, even if their topics are derived from the human reality and the environmental conditions surrounding. It is a creative work of creating imagination that builds on idea, plot, characters, conflict, and raises in the human psyche a mixture of feelings, suspense, excitement, and pleasure (Dowidar, 2005). As for the issue of the relationship between culture and social life holds a lot of controversy, where many researchers see that sociology is interested in studying social relationships that are the fabric of an integrated society, especially when studying social change. But sociology cannot ignore the profound effects of culture, especially now. Cultural change now is directe to the invention and the long-term technological changes that it contributes to rearrange social relations, set new rules and goals for social behavior (Barakat and Hussain, without). Social values represent an important component of the culture of society, they represent all that has meaning in the appreciation and conscience of members of this society and its groups of topics, principles and conditions that they believe in their health or lack of validity, which links these values with the ideas of people in society. Based on the foregoing, the culture of society affects the behavior and actions of its individuals, and this is not evidenced by the difference in the behavior of people in a culture from another culture in terms of values, beliefs and customs. A person is born without language, no values, ideas, or education. But it absorbs these cultural elements, and it acquires them from the society in which it lives, and culture in its most dynamic elements provides us with what achieves our adaptation and adaptation to natural and social environments and distinct formation, and thus culture is one of the most important sources of social values that members of society follow, and a departure from the norm among individuals Society. There is no doubt that these values are derived from the culture of society. People agreed on their followers, and individuals were familiar with them in their dealings with one another, until they formed a necessity for their followers and not departing from them (Ahmed Sanaa and Muhammad, 2008). Television drama is also a real force that can reinforce the value system in society and provide people with how to behave in certain situations. It can also legitimize desired behavior and purify it 
from all aspects of anti-social behavior through what it presents to the issues and issues of concern to the family, which is thus They are close to the audience and viewers can adopt the behaviors presented by dramatic characters on television in dealing with social reality issues (AbdulAziz Rabab, 2010). Which makes it necessary to take an interest in studying the content of television drama, to participate in changing behavioral habits and modifying moral values by presenting role models and human patterns, and addressing societal problems through dialogue and visual image (Ali Samia and Sharaf, 1999). The importance of television drama also stems from the ability of the dramatic message to overcome the barriers of illiteracy through to the masses, and the message is implemented to its audiences and influenced them in a direct way, because the drama derives its material from life, including experiences and situations (Reda, 2002: 30), where television drama is considered a tool One of the tools for influencing society to be enjoyable is a component of attracting attention and effective effect stemming from its embodiment of life and human issues in all its forms and levels, and despite the demand of most of the family for such dramas, there is fear of some of the contents that provide for fear of penetration and its effects on peoples (AlAzzawi and Amal, 2008). Both Shawi and Ismail agreed that the impact studies have shown that the effects appear in the form of a change in the audience receiving knowledge, trends, or patterns of behavior, and from here the impact can be determined in the following areas: 1.
Impact on knowledge: This occurs on the audience's information, so news may be its main source. 2. Influencing the audience's attitudes: It occurs in the public's tendencies, positively or negatively, and affects what it can later approve, and if the message is disturbed, that effect may not occur. 3. Influencing behavior patterns: It is intended to influence the behavior and behavior of the recipient audience according to the interests pursued by the means of communication, and it is the highest level of influence (Ismail, 1998; Shawi, 2003). It is important to realize that these changes in the audience are intertwined with each other, and that the change in knowledge leads to a change in trends and every change in trends often results in a change in behavior patterns, and these changes often occur in succession. It is clear from the previous presentation that culture is the set of elements and influences that characterize the behavior of the individual, and directs it in an unconscious way. Among the basic elements that are culture: beliefs, ethics, arts, scientific logic, industry, customs, traditions and ideas and the right intellectual is the one who has a critical and reformist vision and a special awareness Society and the world around it. (Emad, 2006: 32) Culture as consisting of visible and hidden patterns of acquired and transmitted behavior through symbols, which lead to the special achievement of human groups, which appears in the form of products. They can be embodied in the drums to influence society. The study problem can be presented in answering the following questions: 1. What is the degree of 
cultural payoff for drama?, 2. What is the nature of the relationship between personal characteristics and the cultural return of the drama?, 3 . What is the nature of the relationship between the value variables and the cultural return of the drama?. By presenting the study problem, the study aims to: 1. Learn about the level of cultural payoff for drama. 2. Identify the personal characteristics that influence the cultural returns of the drama. 3 . Identify the value variables that influence the cultural returns of the drama. 4. Explain the relationship between some personal and value variables on the cultural returns of the drama.

\section{Materials and methods}

\subsection{Research hypotheses}

\subsubsection{The first hypothesis}

There is Correlational relationship between the following personal variables: (age, marital status, educational status, profession, number of children, family type, and income level) and the degree of cultural payoff.

\subsubsection{The second hypothesis}

There is Correlational relationship between the following value variables: (the type of social values, the importance of social values, methods of addressing social values, the degree of rooting of social values, the value orientation toward drama) and the degree of cultural reflection.

\subsection{Systematic procedures for the study}

Field of study and method of selecting a sample: 1. Geographical area: Talla village, Minia departmental in Minia governorate, Egypt.

2. The human domain: It refers to the individuals to whom the field study was applied, and in this study the rural families that were exposed to drama were chosen. 3. Time domain: means the time period during which field data was collected, as field data was collected in the period from April to May of 2017. 4. Sample selection method: All families were counted in Talla village, and a simple random sample has been taken that represented $1 \%$ of the total number of families in the village, so the sample size reached (150) families. 5. Type of study and method used: This study is considered a group of descriptive and analytical studies because it was based on describing the study community and analytical by selecting causal hypotheses related to the cultural reflection and it depends on the social survey method in the partial sample through standardized or semi-standardized interviews on a randomly selected sample from the study community. It also depends on the case study methodology as it is studying Talla village, Minia governorate, Egypt. 6. Data collection tools: The study relied on collecting the necessary data for it on the interviewers' personal interview with the application of the questionnaire form that was designed for that to measure the research variables. The questionnaire was 
initially pre-test on 20 respondents from Talla village to ensure the validity of the questions and the respondents' understanding of them to obtain the required responses with accuracy, and the required adjustments were made. The form was designed in its final form. 7. Statistical analysis tools: In light of the objectives of the research, as well as the nature of the data and the level of measurement of the variables in question, some descriptive statistical tools, percentages, and number to describe the demographic, social and economic variables in that research. Also, the "person correlation coefficient" was used in the case of the variables that were measured by a yardstick (quantity) to determine the nature of the relationship between the independent variables of the subjects and the studied dependent variables.

\subsection{Study variables, procedural definitions, and how to measure them}

This part deals with procedural definitions of study variables and how to measure them in the form, as follows

\subsubsection{The dependent variable}

The cultural reflection of the Egyptian drama: this variable means the amount of change that occurs in the culture of society through changing the cultural concepts of society. This variable was measured through the following some axes this is: 1. the degree of influence on the way of thinking: It means the extent of the change of the minds of individuals after exposure to the drama. This variable was measured through the use of a scale consisting of four degrees: very strong influence, strong influence, to some extent influence, uninfluenced, and the responses were given the following weights, 4, 3, 2 and 1 on respectively. 2 . The degree of behavioral impact of the drama: It means the extent of the behavior of individuals as a result of being affected by the drama. This variable was measured by using a scale of three degrees: strong of influence, to some extent influence does not influence and the responses were given the following weights $3,2,1, \quad$ on respectively. 3. The degree of influence on changing concepts: It means the extent of changing some concepts through the concepts explained by some series. This variable was measured through the use of a scale consisting of four degrees: strongly agree, agree, to some extent agree, and disagree. The responses were given the following weights: $4,3,2$, and 1 on respectively. The study considered the total of sum degrees of the previous three axes as an indication of the degree of cultural reflection.

\subsubsection{Independent variables and their methods of measurement}

Personal variables: These studies are represented in: age, gender, marital status, educational status, profession, 
number of children, family type, and level of income.

\subsection{Methods for measuring variables}

\subsubsection{Age}

It means the present age of the respondent as measured by the number of raw years when conducting the study. The age was distributed in categories which are: 15-30 years old, 31- 45 years old, 46-65 years old and over 65 years old, and it has been coded 1, 2, 3, and 4 on respectively.

\subsubsection{Marital status}

It means the marital status of the respondent at the time of application of the form, is he (single, married, divorced and widowed) and coded for her by symbols 1, 2, 3, 4, on respectively.

\subsubsection{Educational status}

It refers to the number of years of formal education for the subject according to the last level of education reached by the father or mother.

\subsubsection{Job}

It means the economic activity practiced by the respondent, is it (farmer, employee, craftsman, free business) and coded for it 1,2, 3 and 4 on respectively.

\subsubsection{Family type}

It means the family type of the respondent whether it is a simple family or a complex family coded 1,2 and 3, respectively.

\subsubsection{Number of children}

This variable is measured by an absolute number of male and female children.

\subsubsection{Income level}

This variable is measured by the number of money the respondent gets in month.

\subsection{Values variables}

The type of social values, the importance of social values, methods of dramatic treatment of issues, the degree of entrenching of social values, the value direction.

\subsubsection{Type of social values}

It refers to the types of values to which the drama is exposed in the form of social series. It was measured through the respondent's responses to the type of social values and the positive and negative values of the drama. The total sum of the values and types of negative and positive values were calculated.

\subsubsection{The importance of social values}

It means the respondent's opinion on the importance of social values through five phrases and his response to them.

\subsubsection{Methods of treatment social values} by social drama

This variable means the causes and 
methods by which social serials treatment social values and measured by satisfying the opinion of the respondent in seven phrases. Revolving around the reasons and methods by which the values are treated in series, using a scale consisting of four degrees: strongly agree, agree, to the extent what agree and disagree. Responses were given the following weights $4,3,2$ and 1 on respectively in the case of positive expressions and vice versa in the case of negative expressions and range ranges (28-7) degree.

\subsubsection{The degree of entrenching social values in the drama}

This variable means the degree of concentration of the drama to influence values that social serials treatment social values and measured by satisfying the opinion of the respondent in four phrases revolving around the suitability of the drama to influence social values in the series, using a scale consisting of four degrees: strongly agree, agree, To some extent agree, disagree, and responses were given the following weights $1,2,3$ and 4 in the case of positive statements and vice versa in the case of negative phrases and the range ranged (4-16) degree.

\section{Results and Discussion}

\subsection{Degree of the value trend}

This variable means the trend towards the type of values that social serials address social values and was measured by satisfying the respondent's opinion of positive or negative values.

\subsubsection{Regarding personal variables}

\subsubsection{Age}

Table (1) showed that the age groups are distributed in a proportionate way, since most of the study sample falls into the category of (45:31) years, and this is logical as this stage is the one that is more concerned with drama and watching TV.

Table (1): Distribution of respondents according to age groups.

\begin{tabular}{|l|l|l|l|}
\hline No. & Age of groups & Number & Percentage \\
\hline 1 & $(15-30)$ years & 51 & 34 \\
\hline 2 & $(31-45)$ & 56 & 37.4 \\
\hline 3 & $(46-65)$ & 34 & 22.6 \\
\hline 4 & Older than 65 years & 9 & 6 \\
\hline Total & 150 & 100 \\
\hline
\end{tabular}

Source: questionnaire form. $\mathrm{N}=150$.

\subsubsection{Marital status}

The results of the study presented in
Table (2) showed that most of the sample members are married (66\%), and they are the group that is interested in hearing 
drama series, and the rest of the percentages are distributed among other groups. It is clear that the percentage of divorce is high in the study sample and represents $6.7 \%$ of the respondents.

\subsubsection{Education level}

Table (3) showed that there is a large percentage of individuals in the study sample who have high educational qualifications about $27.3 \%$, which confirms that the education rate is high among respondents and that the percentage of above-average and medium education among the sample individuals is $29.3 \%$, which is a high percentage of what Confirms the high level of education among the sample members.

\subsubsection{Occupation}

The results recorded in Table (4) showed that the highest percentage of respondents work in public jobs even though they live in rural areas, as $39.4 \%$ of respondents are employees, and $29.3 \%$ are self-employed, and $12.7 \%$ are farmers. This is confirmed by the high percentage of culture among the respondents.

Table (2): Distribution of sample individuals according to marital status.

\begin{tabular}{|l|l|l|l|}
\hline No. & Marital status & Number & Percentage \\
\hline 1 & single & 26 & 17.3 \\
\hline 2 & Married & 99 & 66 \\
\hline 3 & divorced & 10 & 6.7 \\
\hline 4 & Widower & 15 & 10 \\
\hline Total & 150 & 100 \\
\hline
\end{tabular}

Source: questionnaire form. $\mathrm{N}=150$.

Table (3): Distribution of sample individuals according to educational status.

\begin{tabular}{|l|l|l|l|}
\hline No. & Education level & Number & Percentage \\
\hline 1 & Illiterate & 4 & 2.7 \\
\hline 2 & Read and write & 18 & 12 \\
\hline 3 & Middle Certification & 44 & 29.3 \\
\hline 4 & Above Middle Certification & 36 & 24 \\
\hline 5 & high education & 41 & 27.3 \\
\hline 6 & Above the university education & 7 & 4.6 \\
\hline Total & 150 & 100 \\
\hline
\end{tabular}

Source: questionnaire form. $\mathrm{N}=150$.

Table (4): Distribution of the sample population according to the profession.

\begin{tabular}{|l|l|l|l|}
\hline No. & Occupation & Number & Level of education for the mother $(\%)$ \\
\hline 1 & Farmer & 19 & 12.7 \\
\hline 2 & Officer & 59 & 39.4 \\
\hline 3 & He works with his hands & 28 & 18.6 \\
\hline 4 & free business & 44 & 29.3 \\
\hline Total & 150 & 100 \\
\hline
\end{tabular}

Source: questionnaire form. $\mathrm{N}=150$. 


\subsubsection{Family type}

It is clear from the data of Table (5) that the majority of the sample's members are from simple families, as they represent $81 \%$ of the sample's items, and that a small group of the sample's individuals represents $25.3 \%$ belonging to complex families. The countryside tends to decline in light of the current social and economic changes that the rural community is going through, and that almost $20.7 \%$ of the extended families.

\subsubsection{Number of children}

The results of Table (6) showed that (36.7\%) of the respondents are without children, and that $10 \%$ have more than two children. This is consistent with the average age of the respondents.

\subsubsection{The level of income}

The results of Table (7) showed that most of the respondents $(64.1 \%)$ have an income ranging between 1000_2000 pounds, and this is the level of ordinary income for employees in Egypt.

\subsubsection{Value variables}

3.1.2.1 Type of values, customs and traditions

The data recorded in Table (8) Indicated that serials have an effect on social values of $32 \%$. As for economic values, respondents emphasized 19.3\%. As for customs and traditions, 34\% were forgotten. As for environmental values, the opinion is almost the same. This confirms that the values are affected by social series.

Table (5): Distribution of the sample members according to the type of family.

\begin{tabular}{|l|l|l|l|}
\hline No. & Family type & Number & Percentage \\
\hline 1 & Simple & 81 & 54 \\
\hline 2 & Complex & 38 & 25.3 \\
\hline 3 & Extended & 31 & 20.7 \\
\hline Total & 150 & 100 \\
\hline
\end{tabular}

Source: questionnaire form. $\mathrm{N}=150$.

Table (6): Distribution of respondents according to the number of children.

\begin{tabular}{|l|l|l|l|}
\hline No. & Categories & Number & Percentage \\
\hline 1 & Without sons & 55 & 36.7 \\
\hline 2 & One son & 39 & 26 \\
\hline 3 & Two sons & 41 & 27.3 \\
\hline 4 & More than Two sons & 15 & 10 \\
\hline Total & 150 & 100 \\
\hline
\end{tabular}

Source: questionnaire form. $\mathrm{N}=150$. 
Table (7): Distribution of respondents according to the income level.

\begin{tabular}{|l|l|l|l|}
\hline No. & Categories & Number & Percentage \\
\hline 1 & From $(1000-1500)$ & 55 & 36.7 \\
\hline 2 & From $(1501-2000)$ & 56 & 37.3 \\
\hline 3 & From $(2001-2500)$ & 23 & 15.3 \\
\hline 4 & From $(2501-3000)$ & 11 & 7.3 \\
\hline 5 & More than 3000) & 5 & 3.4 \\
\hline Total & 150 & 100 \\
\hline
\end{tabular}

Source: questionnaire form. $\mathrm{N}=150$.

Table (8): Distribution of the sample population according to the type of values, customs and traditions affected by social series.

\begin{tabular}{|l|l|l|l|}
\hline No. & Type values & Number & Percentage \\
\hline 1 & Social values & 48 & 32 \\
\hline 2 & Economic values & 29 & 19.3 \\
\hline 3 & Customs and traditions & 51 & 34 \\
\hline 4 & Environmental values & 22 & 14.7 \\
\hline Total & 150 & 100 \\
\hline
\end{tabular}

Source: questionnaire form. $\mathrm{N}=150$.

\subsubsection{Methods to treatment values in drama}

Table (9) showed that the vast majority of respondents affirm that social series deal with life matters, where $35.4 \%$ of respondents represent this view, $19.3 \%$ affirm that it deals with love and romance, and the same percentage of respondents affirm that it deals with poverty and unemployment, while $26 \%$ of respondents affirm that it deals with marital relations.

\subsubsection{The level of cultural reflection drama}

The data recorded in Table (10) showed that $46.7 \%$ of the respondents changed some of their culture in a high degree, that $33.3 \%$ of their culture was changed to a moderate degree, and that $20 \%$ of the respondents changed their culture change to a low degree, which confirms that the countryside More adhering to the concepts inherited by society.

\subsubsection{The statistical hypothesis test of significance}

\subsubsection{The correlational relationship} between the degree of cultural reflection drama and personal variables

Regarding the statistical hypotheses from (1-8), Pearson's simple correlation coefficient was used to test the relationship between the degree of cultural reflection and individual variables separately, and by testing the significance of this relationship, the results of Table No. (11) Indicated that the significance of the relationship between the degree of cultural reflection and age was proven. The marital status, the number of children, and at a level of 
significance 0.01 , where the value of the correlation coefficient was $0,288,0,289$, 0.258 , and the significant relationship between the degree of cultural reflection, gender, profession, and family type was proved at a significant level of 0.05 , where the value of the correlation coefficient was $0,192,0,191$. 0,194.

Table (9): Distribution of the sample population according to the methods that are treatment by social series.

\begin{tabular}{|l|l|l|l|}
\hline No. & Treated & Number & Percentage \\
\hline 1 & Love and romance & 29 & 19.3 \\
\hline 2 & Marital relations & 39 & 26 \\
\hline 3 & Poverty and unemployment & 29 & 19.3 \\
\hline 4 & Life matters & 53 & 35.4 \\
\hline Total & 150 & 100 \\
\hline
\end{tabular}

Source: questionnaire form. $\mathrm{N}=150$.

Table (10): Distribution of the sample population according to the type of values, customs and traditions affected by social series.

\begin{tabular}{|l|l|l|l|}
\hline No. & The level of cultural payoff for drama & Number & Percentage \\
\hline 1 & High level $(31-24))$ & 70 & 46.7 \\
\hline 2 & Intermediate level $(23-16))$ & 50 & 33.3 \\
\hline 3 & Low Level $(15-8))$ & 30 & 20 \\
\hline Total & 150 & 100 \\
\hline
\end{tabular}

Source: questionnaire form. $\mathrm{N}=150$.

Table (11): Results of the correlational relationship between the degree of cultural reflection and personal variables.

\begin{tabular}{|l|l|l|l|}
\hline No. & Assumption number & Correlation coefficient & Level of significance \\
\hline 1 & 53 & $0,288^{* *}$ & 0,01 \\
\hline 2 & 54 & $0,192^{*}$ & 0,05 \\
\hline 3 & 55 & $0,289^{* *}$ & 0,01 \\
\hline 4 & 56 & 0,044 & - \\
\hline 5 & 57 & $0,191^{*}$ & 0,05 \\
\hline 6 & 58 & $0,258^{* *}$ & 0,01 \\
\hline 7 & 59 & $0,194^{*}$ & 0,05 \\
\hline 8 & 60 & 0,101 & - \\
\hline
\end{tabular}

Based on the previous results, the statistical hypotheses related to the following independent variables are rejected: age, marital status, number of children, gender, and profession. Alternative hypotheses are accepted, and the rest of the statistical assume.

\subsubsection{The correlational relationship}

between degree of cultural reflection and valuable variables

From the second hypothesis, which states that there is a correlation between the degree of cultural reflection and the studied value variables, five statistical hypotheses have been derived. In order to test the significance of the relationship 
between the degree of cultural reflection and the value variables separately, the simple correlation coefficient of Pearson was used.

Table (12): Results of the correlational relationship between the degree of cultural reflection and personal variables.

\begin{tabular}{|l|l|l|l|}
\hline No. & Assumption number & Correlation coefficient & Level of significance \\
\hline 1 & 10 & $0,180^{*}$ & 0,05 \\
\hline 2 & 11 & 0,109 & - \\
\hline 3 & 12 & 0,078 & - \\
\hline 4 & 13 & $0,288^{* *}$ & 0,01 \\
\hline 5 & 14 & 0,010 & - \\
\hline
\end{tabular}

The results of Table (12) indicated that the significance of the relationship between the degree of cultural reflection and the degree of social values rooted was demonstrated at a level of significance of 0.01 where the value of the correlation coefficient was $(0,288)$, and the significant relationship between the degree of cultural reflection and the type of social values was proven at 0.05 level, where the value of the correlation coefficient was 0.180. Based on the previous results, the statistical hypotheses related to the following independent variables are rejected: the type of social values, the degree of originality of social values, and the acceptance of alternative hypotheses. The rest of the statistical assumptions cannot be rejected. Based on the results of research, the following can be recommended: 1 . Paying attention to the media by television and what is not published or send it to the community, 2 . Spreading social values that society maintains through social soap operas, 3 . Not publishing negative values unless it is shown that the drama addresses them, 4. Spread awareness of the importance of choosing a beneficial drama for society.

\section{References}

Abdel-Aziz Rabab, E. (2010), The role of film movies and TV series in addressing the socio-economic problems of egyptian women an analytical and field study, $\mathrm{PhD}$ Thesis, Department of Radio and Television, Faculty of Mass Communication, Cairo University, Cairo, Egypt.

Ahmed Sanaa, and Muhammad, A. M. (2008), A study of some socio cultural values of the inhabitants of an urban area in Assiut in light of Oscar Lewis's theory of poverty culture, PhD Thesis, Department of Sociology, Faculty of Arts, Assiut University, Assiut, Egypt.

Al-Azzawi Amal, H. (2008), "Arab women's uses of dubbed soap operas and verified rumors: a field study", Egyptian Journal of Media Research, Vol. 32.

Al-Masry, E. A. (2010), Television
Drama (components and technical 
controls), Master's Thesis, Arabic Department, Faculty of Art, The Islamic University, Gaza, Palestine.

Barakat, M. M. and Hussein, A. I. , The rural meeting.

Dewidar, D. A. (2005), With that unknown television, First Edition, Publishing and Distribution House, Egypt.

Ismail, M. H. (1998), Principles of Communication Science and Theories of Impact, Dar International Library, First Edition, Cairo, Egypt.
Reda, A. S. M. (2002), The dramatic building in radio and television, Arab Thought House, Beirut, Lebanon.

Shawi, B. (2003), Introduction to mass communication and its theories, First Edition, Dar Al-Kindi, Irbid, Jordan. 